Parents' Mobile Relational Maintenance in Resource-Constrained Contexts: Barriers and Facilitating Access Conditions

\author{
Alcides Velasquez \\ University of Kansas
}

Alcides Velasquez, Ph.D., Department of Communication Studies, The University of Kansas avelasquez@ku.edu 


\title{
Parents' Mobile Relational Maintenance in Resource-Constrained Contexts: Barriers and Facilitating Access Conditions
}

\begin{abstract}
Mobile phones have become central to family members' daily communication. This study investigates the material and skills access barriers that parents of adolescents in resourceconstrained contexts face for mobile relational maintenance. Following an exploratory sequential mixed-methods design, interviews with parents in Bogotá, Colombia explored how they managed to keep in touch with their children despite facing access barriers and how these barriers still affected their parent-child mobile interactions. A survey was conducted in the quantitative phase to confirm the relationship patterns suggested by qualitative findings. Financial, cognitive, and environmental resources constituted access barriers. Despite gaining material access through alternative social and environmental resources, the barriers they faced still influenced the nature and frequency of their parent-child mobile interactions. Findings also showed that cognitive barriers, observed as parents' low levels of perceived capability to learn how to use mobile phones, affected parents' text messaging through their acquisition of skills.
\end{abstract}

\section{Keywords:}

Mobile relational maintenance, access barriers, resource-constrained contexts, digital divide, skills, mobiles, efficacy 


\section{Parents' Mobile Relational Maintenance in Resource-Constrained Contexts: Barriers and Facilitating Access Conditions}

Mobile phones have become central to family members' daily communication routines. They facilitate parents' parent-child communication goals, including monitoring (Barron, 2014), coordination (Crosswhite et al., 2014), and affection and support (Devitt and Roker, 2009). However, this is based not only on the assumption that parents own a mobile phone, but also that they possess the skills to operate it. What happens when these assumptions cannot be taken for granted?

Mobile phone use has surpassed that of computers (ITU, 2014). However, access to and use of mobile phones is limited in resource-constrained contexts (Gonzales, 2014). A resourceconstrained context is one in which people regularly face scarcity of the means needed to pursue their livelihood. Three of every ten adults in the U.S. who make less than $\$ 30,000$ a year do not own a smartphone (Anderson, 2017). Smartphone subscriptions are much lower in developing countries than in developed countries (ITU, 2014).

This study conceptualizes access to mobile phones as a multidimensional construct, influenced by material availability, motivation and skills (van Dijk, 2005). Skills refers to the knowledge necessary to operate the hardware and software, evaluate the information people encounter (van Dijk, 2005: 72), and interact with others through information technologies. The skills someone possesses affect the activities they engage in online, what they do with the information, and how they communicate with others (Helsper and Eynon, 2013; van Deursen et al., 2014).

This study assumes that parents of adolescent children are highly motivated to be in touch with their children while away from home. I focus on the question: how do parents, in situations 
of limited resources for material access and skills, still communicate with their adolescent children in their daily life using mobile phones?

A human ecological approach (Blumer, 1986; Sampson, 2012) enables the observation of interplay between the environment and human behavior, revealing how the environment and individual attributes can shape human choices. Such an approach emphasizes the importance of human agency and how and what choices people make in order to achieve their self-determined goals (Katz and Gonzalez, 2016).

The context of this study is Bogotá, Colombia. Like in the rest of the world, mobile phone subscriptions in Colombia have been growing steadily. Currently, mobile phone penetration exceeds $100 \%$ of the population, but only around 35\% own a smartphone (MinTIC, 2015).

Research on parent-child mobile maintenance has focused mostly on samples from North America and Europe (Mascheroni and Ólafsson, 2015; Rudi et al., 2015; Schon, 2014). The study of mobile maintenance in emerging economies can contribute to our understanding of mobile media and communication (Pearce, 2013) by providing a broader picture of mobile communication as a global phenomenon and of the novel ways people gain access to mobile phones. In sum, this study brings questions of material and skills access to the forefront in parent-child mobile maintenance research. It focuses on parents' communication choices and behaviors given their barriers and available alternative resources.

This study followed an exploratory sequential mixed methods design (Creswell, 2014: 219). In the qualitative phase, I explored how parents experienced access barriers, how they navigated their particular circumstances to communicate with their children, and how those barriers affected their mobile phone use and communication behaviors. Data for the first phase was collected using semi-structured interviews with parents of adolescents. The quantitative phase 
built on the results from the interviews. I surveyed parents of adolescents to confirm the relationships suggested by findings in the qualitative phase.

\section{The context}

Households in Bogotá are classified into one of six social strata as a proxy for socio-economic status, based on the internal and external characteristics of the dwelling and its surroundings (DANE, n.d.). It is estimated that around $9.5 \%$ of the population live in very low social strata neighborhoods, $39.3 \%$ in low, $35.7 \%$ in mid-low, $9.45 \%$ in middle, $2.6 \%$ in mid-high, and $1.7 \%$ in high (Secretaría Distrital de Planeación de Bogotá, 2015) (SDPB).

Bogotá has a high level of inequality compared to other South American cities. The Gini coefficient for Bogotá in 2014 was 0.503 (DANE, 2015), higher than other Latin American cities such as Caracas, Quito, and Lima. (UN-Habitat-United Nations Human Settlements Programme, 2011).15.8\% of the population are still considered poor and $4 \%$ are considered extremely poor (SDPB, 2015).

Around $40 \%$ of the population in Bogotá have access to the Internet (SDPB, 2015). However, only $38 \%$ of households in low strata (i.e. very low, low and mid-low social strata), compared to $90 \%$ in higher strata (i.e. mid, mid-high and high), have broadband or mobile Internet access.

People spend more time commuting for work in Bogotá than in any other city in Latin America (INRIX, 2016). Commuting times on public transportation are above two hours per day. People who live in lower social strata neighborhoods use public transportation twice as much as those who live in higher socio-economic strata neighborhoods (Secretaria Distrital de Movilidad, 2016). This makes mobile phones the most efficient communication alternative for families and 
emphasizes the importance of understanding what are the barriers and facilitating conditions that allow parents to keep in touch with their children during the day.

\section{Types of Access, Barriers, and Facilitating Conditions}

Although several authors have proposed different digital divide models (DiMaggio et al., 2004; Helsper, 2012; Selwyn, 2004), we adopt van Dijk's (2005) as an interpretative framework. Van Dijk (Dijk, 2005: 22) divides the concept of access into four successive kinds of access: motivational access, material access, skills access, and usage access. As this study assumes parents are motivated to use mobile phones for daily interactions with their children, we explore how the lack of certain resources create material and skills access barriers and how parents gain material and skills access through alternative resources.

Coined by some researchers as second-level digital divide (Hargittai and Hinnant, 2008), Internet skills have become a focus in digital divide research (see Litt, 2013 for a review). Skills play an influential role in digital inequalities, as they affect how individuals use the Internet (Hargittai, 2010; Helsper and Eynon, 2013) and the outcomes they get from this use (van Deursen et al., 2014; van Deursen and Helsper, 2015, 2017).

However, digital divide has not particularly focused on mobile skills and how they might affect use. Although conceptualized as a dimension of Internet skills (Deursen et al., 2016), the construct of mobile skills requires further development and consideration. As mobile Internet has become more common, mobile skills are expected to shape Internet and mobile technology use and outcomes. The paucity of research on mobile skills have found it is related with frequency of use (Park, 2015). Therefore, while the concept of skills has become central to the study of digital inequalities, more research is needed on mobile skills. As this study focuses on the different 
barriers parents face for mobile interaction with their children, we expect mobile skills to potentially emerge as one of the barriers.

In van Dijk's model, each type of access is facilitated by a set of available resources. Resource is defined as the "available means that are used as a source of supply to support in accomplishing particular aims" (van Dijk, 2005: 36). The framework identifies five different categories of resources: (1) temporal—-the time to engage in online activities, (2) material— the ownership of goods that enable access, (3) mental - the knowledge and cognitive and emotional predispositions to use the technology, (4) social-the social contacts who serve as sources of knowledge and advice, and (5) cultural — the norms, lifestyles, hobbies, and status within a social group that influence adoption decisions. Barriers for each access type are generated by a lack of resources.

\section{Digital Divide and Parent-Child Mobile Maintenance}

The transition from childhood to adulthood marks important changes as adolescents detach emotionally from parents and seek more autonomy (Steinberg, 2001). These changes make parents more invested in routinely contacting their children. Inter-personal communication motives suppose that people have certain goals and intentions when they interact with others. In family contexts, the most common communication motives are affection, pleasure, and inclusion (Barbato et al., 2003).

Previous research in parent-child mobile communication has illustrated the importance of mobile phones for family communication rituals in places such as Norway (Ling, 2006). Other studies showed how families in the U.K. (Devitt and Roker, 2009) and in Israel (Ribak, 2009) find mobile phones useful in situations of emergency. Research has noted the importance of mobile technologies to enable permanent contact between family members in places such as the U.S. 
(Crosswhite et al., 2014), Taiwan (Wei and Lo, 2006), Australia (Wajcman et al., 2008), and Denmark (Christensen, 2009).

When mobile parent-child communication is studied in resource-constrained contexts, other factors that intervene in families' communication practices are forefront. Ureta (2008) found that, among low-income families in Chile, mobile phone use was restricted to urgent matters only. Other studies emphasize how environmental factors affect adoption and modes of use. Katz and Gonzalez (2016), in a qualitative study that examined how different macro- and meso-level factors influenced technology adoption decisions and how families viewed and used technology, illustrate how factors such as immigration law enforcement, safety concerns, and cultural norms at school affected families' decisions about how to engage with those technologies.

Madianou and Miller (2011), in a study that looked at experiences of Philipino migrant mothers in the U.K. and left-behind children with communication technologies, showed how the place of access influenced individuals' experience with the technology. The differences in experience were related to access asymmetries between the U.K and the Philippines.

In sum, studies at the intersection of digital divide and parent-child communication suggest that financial, environmental, and motivational factors shape adoption, skills acquisition, and types of use. The qualitative phase of this study explored how the lack of certain resources was related to material and skills access and how, in order to achieve their parent-child communication objectives, participants tried to overcome those barriers through alternative resources.

\section{Qualitative Phase Methods}

\section{Participant recruitment.}


This study followed a sequential mixed-methods design (Creswell, 2014, p. 225). Such approach allows to explore the research problem while taking into account the diversity of perceptions, experiences, and context of participants. The quantitative phase examined whether the qualitative findings were limited to the idiosyncrasy of the sample or represented the population in Bogotá who lived in resource-constrained contexts.

Some participants were recruited by contacting parents of teenage children in two lowincome public schools in Bogotá. Other participants were recruited by contacting public and private schools that served low-, mid-, and high-strata populations based on information from the Secretary of Education (Secretaría Distrital de Educación de Bogotá, 2017). A few individuals who lived in higher social strata households were included because I suspected that the barriers people faced were not limited to lack of financial resources. This phase of the study followed a purposeful criterion sampling method (Palinkas et al., 2013) to recruit participants who: (1) were parents of an adolescent, (2) spent most of the day away from home, and (3) were invested in communicating with their child on a regular basis.

A total of twenty one-hour long semi-structured interviews were conducted with parents of children between the ages of 13 and 18 years old. Interviews took place at a location chosen by the interviewee. The average age of parents was 43.5 years old. Seventeen parents were females, and three were males. Table 1 shows demographic information for interviewed parents. 
Table 1. Demographics for interviewed parents

\section{Gender}

Female

17

Male

3

\section{Marital status}

Married

10

Divorced

3

Widow

1

Living with partner 2

Single 4

\section{Social strata}

Low $(1,2,3)$

10

Mid (4)

7

$\operatorname{High}(5,6)$

3

\section{Interview protocol.}

Participants were asked about the different technologies they used to communicate with their children, the barriers they faced when trying to use these technologies, and how they tried to solve these barriers. Interviews were recorded and then transcribed. I iteratively coded under emerging categories (Onwuegbuzie and Leech, 2006). A codebook was developed including definitions for codes and example quotations (Guest et al., 2011: 52). Codes were interpreted and 
grouped into categories, then organized into a conceptually clustered matrix (Miles and Huberman, 1999: 128). The matrix included a summary of the coded segment for each participant.

\section{Analysis and Results}

I identified three categories of resources-financial, environmental, and cognitive - that, when absent, generated barriers for material and skills access. Although parents turned to alternative available resources, the presence of these barriers ultimately affected parents' mobile interactions with their children.

\section{Material Access.}

This section describes barriers and alternative resources for material access.

Barriers for material access. I identified financial and environmental material access barriers.

Financial resources. This barrier became apparent only for owning smartphones and for having data or voice plans. Some parents said it was not financially feasible for them to acquire a smartphone or to subscribe to a voice or data plan. Alba is single and lives with her sixteen-yearold son. They share a house located in a very low social stratum district with Alba's aunt, her husband, and their children. She works as the cleaning lady in a house. She leaves home before her son wakes up. The rest of Alba's family lives in another city, and sometimes her son spends long periods of time with them. Money is an important concern when she wants to say hello to her son and check if he is all right: "To be able to talk or chat, well, it depends on the budget that I have. If I do not have money to buy voice minutes or data, I have to limit my conversations." $(\text { Alba })^{1,2}$

Environmental resources. Environmental barriers consisted of perceptions that it was unsafe to own a mobile phone or a smartphone or to use one in the streets. 281,000 mobile and 
smartphones were reported stolen in Bogotá in 2017 (Direccion de Investigacion Criminal e Interpol-Policia Nacional de Colombia, 2018). In 2016, of every four robberies reported, one was a mobile phone (Direccion de Investigacion Criminal e Interpol-Policia Nacional de Colombia, 2017).

Some of the participants perceived this issue as a barrier for having or publicly using a mobile phone. Luz lives with her partner, her two children, and her granddaughter in a house located in a very low social strata neighborhood. She likes to always be informed about the whereabouts of her sixteen-year-old son and would enjoy sending him sweet messages. However, he does not have a mobile phone because his parents are afraid he might get mugged and beaten should he use it in a public space. Carmen lives in a very low social strata house with her partner, her three daughters, and her granddaughter. Her oldest daughter is 17 years old and is the mother of a two-year-old girl. Carmen and her mother run a fast-food joint. Carmen likes to be in touch with her teenage daughter and to be informed throughout the day about her granddaughter. But, when she is in the street, she will not answer the phone: "When I am in the street I do not like to answer phone calls. I have seen how a lot of people have been robbed. I would panic." (Carmen).

This fear of using or carrying a mobile phone in public spaces contrasts with what has been observed in developed contexts, where some people have developed high levels of mobile phone dependency (Konok et al., 2016; Lopez-Fernandez et al., 2013), even bringing negative consequences to their relationships (Hall and Baym, 2012; Seo et al., 2016).

These findings show that parents faced financial and environmental barriers, and those affected not only the quantity but also the qualities of their parent-child communication. This is the case for Luz, who could not reach her communication goals because her son did not have a 
mobile phone due to their environment. Parents who faced these barriers were less likely to own a smartphone or a plan and limited the number and nature of their interactions throughout the day.

Alternative resources for material access. Parents, however, navigated around these barriers to gain material access using alternative resources.

Social resources. Those participants whose children did not have mobile phones could still reach their children by calling their children's friends. However, those interactions were mostly limited to learning about the adolescent's whereabouts, affecting the fulfillment of parents' affection motivations. Luz calls either his child's girlfriend or his best friend: "I have the contact information of Tatiana and of 'El Pollo.' I call them and talk to Antonio and tell him not to take too long" (Luz). Lucero lives with her husband and their two children in a mid-low social strata apartment. She monitors her seventeen-year-old daughter. She works as an office assistant, so she does not see her child again until she gets back home in the evening. Since her daughter's mobile phone was stolen, she contacts her through her best friend: "Now that they stole her mobile phone I text her best friend and ask her about my daughter to see if she is with her" (Lucero).

Patricia lives together with her husband and their four children in a mid-low social position district. She likes to always know where they are and what they are doing. Usually, they use their social resources as an alternative when her children do not have voice minutes: "When Diana does not have any minutes on her mobile, she asks a friend that has minutes, calls me, and hangs up, and then I know it is her and I return the call." (Patricia).

Environmental resources. We found that the local context offered facilitating conditions for material access. Although services at cybercafés-a type of public access computing (PAC) venue - have a cost, they represent a useful alternative for those who face financial constraints. PAC venues are locations that serve the information and communication needs of underserved 
populations (Baron-Porras and Gomez, 2012). They offer, among other services, access to computers, the Internet, and landline and mobile phone booths (Baron and Gomez, 2013).

Cybercafés allow parents to control how much money their children spend on minutes and also enable children to contact their parents when they need to talk to them. Cristina is a domestic worker who lives with her three children in an apartment located in a low social strata district. When her seventeen-year-old daughter does not come home from school, Cristina wants to know where she is and how she is doing: "Yes, I give her some spare change so she can call me when she's out. When she doesn't call, I get mad at her, because that's when I start imagining something terrible has happened" (Cristina).

These findings illustrate the strategies parents use to navigate the financial and environmental barriers they encounter. Parents who face environmental barriers tend to use their mobile phones less frequently. Those who face financial barriers are still capable of contacting their children using PAC venues and calling a friend's mobile phone. However, in several occasions their communication motivations are limited to monitoring.

\section{Skills Access.}

Possession of skills has been proven to affect how digital technologies are used (van Dijk and van Deursen, 2014). Some participants who did not have skills to use their devices received help from their children but, others felt incapable of acquiring those skills. Their lack of skills affected their use, as they only made phone calls and never text messaged their children.

Based on Social Cognitive Theory (SCT) (Bandura 1997), we called learning efficacy individuals' perceptions of learning capability. Efficacy is defined as an individual's belief in their capability to follow a course of action in order to attain a type of performance (Bandura, 1997). 
Efficacy influences learning processes (e.g. Honicke and Broadbent, 2016). Below we characterize the proposed concept of learning efficacy and its relationship with skills barriers.

Skills barriers. Some participants felt that operating a touchscreen smartphone was very challenging. Many times, they could not do what they intended. Laura is a mother of three and lives in a very low social stratum apartment with her husband. She likes to contact her children on their mobile phones to tell them how much she loves them, but she does not have the skills to text them: "I can't with the touchscreen phone. I have tried in every way. Even every single time I need to answer a call, I end up hanging up (chuckles). That touchscreen is a horrible thing" (Laura).

For others, the touchscreen presented a challenge, but their children or other family members taught them to use it. Mariana lives with her husband and their two children in a midsocial stratum apartment. She works as a PR representative. She explains how she experienced the change from a mobile phone to a smartphone: "It has been tough for my kids, because my husband got me a new mobile and it killed me... . You always need your fingers to do anything with that; it jiggers and makes sounds by itself. . . . Finally I learned how to use it.” (Mariana).

For some participants, it was difficult at the beginning, but circumstances forced them to learn how to use a smartphone:

One must adapt to the new circumstances. Earlier I didn't even know how to answer a phone call on that gizmo. My kids explained me over and over and I couldn't. ... Later on, and little by little, I saw it as necessary, and I even learned how to text when they [her children] explained me how to do it. (Patricia)

Learning efficacy barriers. We identified that some of these participants felt incapable of learning to use a smartphone. Parents who perceived they could not learn also tended to use their mobile phones differently, compared to those who already had the skills. Angela, a widow who 
lives with her sixteen-year-old son in a mid-social strata district, is convinced she cannot learn:

'I find it very difficult. David [her son] tells me, 'Come on! Learn!' But no, I just can't".

(Angela). As a result, she only uses voice calls when trying to communicate with her son, despite recognizing that "he [David] wishes that his mother could send him a text through WhatsApp" (Angela).

When asked about trying to learn how to send a text message, Angela said: "I find it very difficult. I just make phone calls", and added:

"If we are not together, from mobile to mobile; if I can find a land line where to call him, I just do that. No messages with WhatsApp. . . I always tell him, 'Dear son, you know your mom only knows how to answer the mobile phone.' "' Angela)

Cristina shared the same view. When asked about how she used her smartphone, she answered: "No. All those devices, just to answer and make phone calls. . . All those other things. Never. I can’t learn” (Cristina).

Previous studies show how children help their parents learn to use communication technologies (Correa, 2014). Findings in this study point at learning efficacy as a cognitive resource that influences mobile phone use. A lack of this cognitive resource can become a barrier, as it hinders skills acquisition. According to these results, parents who feel less capable of learning how to use a mobile phone either do not ask for help or believe they cannot learn. Therefore, they do not get the skills to use their mobile phones for tasks beyond making phone calls.

\section{Quantitative Phase}

Following qualitative findings, we expect that both environmental and financial barriers will negatively affect smartphone ownership, and that those facing environmental and financial 
barriers will tend to talk less frequently with their children through their own mobile phones. We thus propose the following hypotheses, which we test using survey data:

H1: A negative relationship exists between smartphone ownership and a) financial and b) environmental barriers.

H2: A negative relationship exists between frequency of communication using parent's own mobile phone and a) financial barriers and b) environmental barriers.

Qualitative findings suggested that parents who faced financial and environmental constraints tended to contact their children through others' mobile phones and PAC venues more frequently. Therefore, we hypothesize that:

H3: A positive relationship exists between communication frequency through social connections and a) financial barriers and b) environmental barriers.

H4: A positive relationship exists between PAC venues use and a) financial and b) environmental barriers.

Our results also pointed at the existence of a cognitive resource that, when lacking, affected a specific type of mobile use: text messaging. In contrast to parents who sought help and thought they could actually learn the skills, those parents who did not feel capable of learning restricted their mobile phone use to just phone calls. Therefore, we test the following mediation model (Figure 1):

[FIGURE 1 AROUND HERE]

\section{Sample and data collection.}

Eighteen schools were contacted through RedPapaz, an existing national network of schools. Based on information from the Secretary of Education (Secretaría Distrital de Educación de Bogotá, 2017), we selected schools following the social strata of the student population they 
serve and making sure we kept representative quotas of teenage children from each social stratum. A total of five school principals expressed their interest in the study. Three of the schools were public and served very low, low, and mid-low social strata, and two were private, and served mid, mid-high, and high social strata students. In exchange for their participation, each school added questions to the survey and received a report of the findings. No incentives were offered to parents. Children of the parents who participated in the study were between 14 and 19 years-old. The average age of the children was 16 years old $(S . D .=1.16)$.

\section{Data collection.}

One section per grade, from $8^{\text {th }}$ to $11^{\text {th. }}{ }^{3}$ was randomly selected. In one school, data was collected during parents-teacher conferences. For the other schools, invitations and consent letters were sent with the students in closed envelopes, together with the questionnaire and a return envelope. Children returned the signed consent letter and the questionnaire answered. Invitation letters were constructed following the Tailored Design Method (Dillman, 2007).

\section{Sample.}

Of the 622 surveys that were sent, 298 surveys were completed. The response rate was 47.9\%. Table 2 includes descriptive information for social strata and education. Respondents' mean age was 43.66 (S.D.=7.64). 24.5\% identified as male and $70.8 \%$ as female. $95 \%$ said they had a mobile phone. Because this study focused on resource-constrained contexts, the hypotheses were tested using those participants who lived in households located in very low, low, and middlelow social strata districts. Eight observations had to be excluded from this set because of inconsistent or inattentive responses. The new sample size was $n=216$.

\section{Analysis and results}

\section{Dependent variables.}


Ownership of a smartphone with a corresponding data plan was determined by asking respondents whether they owned a smartphone with a data or voice plan. $48.1 \%$ reported they had one.

Communication frequency using parent's own mobile phone $(\mathrm{M}=4.36$, S.D. $=0.96)$ was determined by asking participants how frequently (1: never, 5: always) they contacted their child using their own mobile phone.

\section{Table 2.}

Percentages for social strata ${ }^{4}$ and education

\begin{tabular}{ll}
\hline Social strata & \\
Very low & $6.4 \%$ \\
Low & $49.3 \%$ \\
Mid-low & $19.5 \%$ \\
Mid & $13.1 \%$ \\
Mid-high & $6.7 \%$ \\
High & $0.7 \%$
\end{tabular}

Education

$\begin{array}{lc}\text { Some elementary } & 2.3 \% \\ \text { Elementary } & 7.7 \% \\ \text { Some high school } & 13.1 \% \\ \text { High school } & 25.5 \% \\ \text { Some college } & 16.4 \% \\ \text { College } & 19.8 \% \\ \text { Graduate } & 9.4 \%\end{array}$

Mobile communication through social connections $(\mathrm{M}=2.60$, S.D.=1.32) was gauged asking participants how frequently (1: never, 5: always) they contacted their child through someone else's phone.

Mobile communication through PAC venues $(\mathrm{M}=2.77$, S.D.=1.49) was measured asking participants how frequently (1: never, 5: always) they contacted their children using a cybercafé, public library or tele-center. 
Mobile texting $(\mathrm{M}=3.13$, S.D.=1.59) was determined by asking participants how frequently (1: never, 5: always) they contacted their child through WhatsApp texts.

\section{Independent variables.}

Each perceived barrier was gauged using the average score of two items. The preface was: "We would like to know how much you agree with the following statements. (1: Totally disagree, 5: Totally agree)."

The items for financial barriers $(\mathrm{M}=2.98$, S.D. $=1.00, \alpha=.41)$ were: "I don't have the money to pay for a smartphone data plan," and, "Minutes to talk over mobiles are expensive."

Environmental barriers $(\mathrm{M}=4.02$, S.D. $=.99, \alpha=.83)$ was operationalized using the items: "It is not safe to use smart or mobile phones in the streets of my neighborhood," and, "It is not safe to use smart or mobile phones in the streets of the city".

Learning efficacy $(M=8.49$, S.D. $=1.66, \alpha=.94)$ was measured using the average score of six items. The preface asked respondents how capable they believed they were of learning how to do a set of activities on mobile phones and smartphones (10: Vary capable, 1: Not capable at all). Items included: "Learn how to use an app on a smartphone," "Learn how to use a smartphone," and "Learn from the explanations of someone about how to connect to a video conference through the smartphone." The items were developed based on the skills interviewees identified as feeling incapable of learning.

Skills $(M=4.03$, S.D. $=.81, \alpha=.93)$ was measured averaging the score of 14 items. Participants were asked to express how much they agreed with each statement (1: Totally disagree, 5: Totally agree). The preface read, "I know..." Some of the items were: "How to connect a smartphone to a Wi-Fi network," "How to send different kinds of files on a smartphone," and 
"How to configure the ringtones on a mobile phone." The items were developed based on interviewees' accounts of tasks they learned, wanted to learn, or could not learn.

\section{Analysis}

Assumptions for regression analysis were examined. The new sample size was $n=191^{5}$ after identifying influential outliers using DFBETAS (Andersen, 2008: 41). Results of OLS regressions are reported using standardized beta coefficients.

\section{Ownership of smartphone with data plan.}

Hypotheses 1a and $1 \mathrm{~b}$ examined the influence of financial barriers and environmental barriers on ownership of a smartphone with a corresponding data plan. After controlling for age, gender, and education, results of a logistic regression (Table 3) showed the perception of financial barriers reduced the likelihood of having a smartphone by $30.9 \%$, confirming hypothesis $1 \mathrm{a}$. However, the coefficient for perceived environmental barriers was not statistically significant. Hypothesis $1 \mathrm{~b}$ was not supported.

\section{Financial, Environmental Barriers and frequency of communication using parent's} own mobile phone.

Hypothesis $2 \mathrm{a}$ and $2 \mathrm{~b}$ examined how financial and environmental barriers negatively affected parents' frequency of mobile communication with their children using their own device (Table 4). Only those participants who reported owning a mobile phone were included in these analyses. Control variables included age, gender, and education level. Results of an OLS show how financial barriers and frequency of communication using parent's own mobile phone are negatively related $(\beta=-.180, p=.035)$, supporting hypothesis $2 \mathrm{a}$. Hypothesis $2 \mathrm{~b}$ was not supported. The relationship between environmental barriers and frequency of communication using parent's own mobile phone was not statistically significant $(\beta=.69, p=.41)$. 
Financial and Environmental Barriers and Communication through Others and through PAC venues.

Results did not support hypotheses $3 \mathrm{a}$ and $3 \mathrm{~b}$ (Table 5). The relationship between financial barriers $(\beta=.127, p=.12)$ and environmental barriers $(\beta=.002, p=.97)$ and communication through others, although positive, was not statistically significant.

Hypothesis 4 was partially supported. As individuals faced more financial barriers, they also reported using PAC venues more frequently to contact their children while away $(\beta=.136, p=.049)$, after controlling for age, gender, and education (Table 5). The relationship between environmental barriers and PAC venues use was positive but not statistically significant $(\beta=.014, p=.83)$. 
Table 3.

Logistic Regression Analysis of Smartphone with Data Plan Ownership

\begin{tabular}{lll}
\hline & $B$ & Odds ratio \\
\hline Age & $-.052^{*}$ & .95 \\
Gender & $1.070^{* *}$ & 2.91 \\
Education & $.433^{* * *}$ & 1.54 \\
Financial barrier & $-.369 * *$ & .691 \\
Environmental barrier & -.043 & 1.04 \\
(Intercept) & .876 & 2.57 \\
\hline Goodness-of-fit & $\chi^{2}=33.138, \mathrm{p}<.001$ \\
Log likelihood & 209.412 \\
Cox \& Snell R Square & .173 \\
\hline$N=175$. Dependent variable smartphone ownership (yes $=1)$. \\
$* p<.05, * * p<.01, * * * p<.001$. \\
\hline
\end{tabular}

Table 4.

OLS regression analyses predicting frequency of communication using parent's own mobile phone.

\begin{tabular}{ll} 
& \multicolumn{1}{c}{$\beta$} \\
\hline Age & .032 \\
Gender (Male) & $-.145^{*}$ \\
Education & .011 \\
Financial Barriers & $-.180 *$ \\
Environmental Barriers & .069 \\
\hline $\mathrm{F}(d f)$ & $1.470(5,162)$ \\
$\mathrm{R}^{2}$ & .043 \\
\hline$* \mathrm{p}<.05, * * \mathrm{p}<.01, * * * \mathrm{p}<.001 . N=167$. & \\
& \\
\hline
\end{tabular}


Table 5.

OLS regression analyses predicting mobile phones access through PAC venues use and social connections by financial and environmental barriers.

\begin{tabular}{lc|c}
\hline & Access through social connections & \multicolumn{1}{c}{ PAC venues use } \\
\hline Age & $\beta$ & $-.143 *$ \\
Gender (Male) & -.027 & $-.148 *$ \\
Education & $-.191 *$ & $-.328^{* *}$ \\
Financial barriers & $-.178 *$ & $.136^{*}$ \\
Environmental barriers & .127 & .014 \\
\hline $\mathrm{F}(d f)$ & .002 & $7.995(5,169)$ \\
$\mathrm{R}^{2}$ & $3.459(5,161)$ & .192 \\
$N=166$. & .097 & $N=174$. \\
\hline$* \mathrm{p}<.05, * * \mathrm{p}<.01, * * * \mathrm{p}<.001$. & \multicolumn{2}{|}{} \\
\hline
\end{tabular}




\section{Mobile use learning efficacy and skills.}

Process Macro (Hayes, 2013) for SPSS was used to test the mediation model. Gender, age, and education were included as covariates. Only those users who reported having a mobile phone were considered in the analysis $(n=172)$. Results indicated that learning efficacy was a significant predictor of skills, $\beta=.23, \mathrm{SE}=.035, p<.001$, and that skills was a significant predictor of mobile messaging, $\beta=1.02, \mathrm{SE}=.165, p<.001$. These results support the mediation hypothesis (Figure 2). Learning efficacy was no longer a significant predictor of mobile messaging after controlling for skills, $\beta=.022, \mathrm{SE}=.086, p=.79$. Approximately $31 \%$ of the variance in mobile messaging was accounted for by the predictors $\left(\mathrm{R}^{2}=.313\right)$. The indirect effect was tested using a bootstrap estimation approach with 5000 samples. The unstandardized indirect coefficient was significant, $\beta=.243, \mathrm{SE}=.0549,95 \% \mathrm{CI}=.1476, .3628$.

[FIGURE 2 AROUND HERE]

\section{Discussion}

As digital divide studies using micro-level approaches focus on individuals' attributes, they do not capture resources present in the environment (Hampton, 2010). A human ecological approach to the observation of parents' mobile relational maintenance allowed us to uncover meso-level resources and how they jointly influence access together with micro-level resource variables. Thus, this study complements van Dijk's (2005) framework by identifying environmental resources that the framework did not initially include and how these resources were related to material access.

The environment in which individuals are placed can influence access and use of mobile phones. In the present study, findings suggested that concerns of getting their mobile phone stolen influenced parents' decisions of ownership (especially for their children) and use of mobile phones in public spaces. However, quantitative results did not confirm the relationship between safety 
concerns and smartphone ownership, frequency of communication using parents' own mobile phone, contact through social connections, or use of PAC venues. The lack of support for these hypotheses can be explained in three possible ways. First, smart and mobile phone robberies in Bogotá have been mostly present in very specific and limited areas of the city. Participants in the qualitative phase and the quantitative phase lived in different areas of the city. Future studies using a representative sample of the city population might lead to more definite results. Another potential explanation is that these concerns affected only ownership of mobile phones for children, a variable that was not included in this study.

Velghe (2012), in a study that examined mobile phone use of middle-aged women from Wesbank, South Africa, found that while mobile phones theft was relatively common, being connected and available seemed to override the risk of carrying a mobile. Therefore, people developed a set of strategies that dictated when and where to use and show their mobile phones, which influenced how they used their devices in public places. It might be that, as Velghe (2012) found, theft concerns affected parents' strategies for how and when they used their mobile phones in public spaces but did not restrict their overall interaction with their children or actual ownership of a device. The benefits of owning and carrying a mobile phone in public may have overridden the costs. More qualitative studies are needed that delve into parents' mobile phone use strategies in public spaces and how they compensate for those environmental restrictions.

Other studies have identified other environmental factors that affect access. Correa and Pavez (2016) found that the geographical location of certain towns in rural Chile affected access, as people in those areas were more isolated, infrastructure was more scarce, and people were less aware of different access possibilities compared to those in big metropolitan areas. De Souza e Silva, et al., (2011) found the environmental circumstances of people living in favelas in Rio de 
Janeiro, Brazil influenced how they appropriated and cannibalized mobile phones, challenging law enforcement. In sum, our findings contribute to the existing idea that circumstances created by individual and environmental conditions give shape to different access choices, building an access ecology that integrates peoples' access limitations and enablers, ultimately influencing how they use technologies. Individuals' attributes should be considered concurrently with environmental factors, as they act jointly to influence access and usage decisions.

As active agents, parents sought alternative ways to achieve their communication objectives, but they were often still unable to meet them. Parents who faced financial constraints interacted less frequently with their children during the day, and, although driven by affection motivations, their interactions reflected monitoring motivations. This is an important communication and relational outcome. Children tend to evaluate interactions that reflect these motivations under a negative light (Hessel et al., 2016).

Our findings also demonstrate how skills influenced how people used their devices. Furthermore, we uncovered learning efficacy as a cognitive resource that facilitates skills acquisition. While studies suggest that seeking help and support from others, especially children, influence skill accruement (Correa, 2014; van Deursen et al., 2014), our findings showed that learning efficacy acted as a necessary cognitive resource for skills learning. This cognitive resource, and not necessarily the skills, might be the barrier affecting some parents.

The notion of efficacy has been used before in digital divide research (Eastin and LaRose, 2000). However, that construct was propounded to explain knowledge barriers to adoption, comfort, and satisfaction using the Internet. Consequently, it has been interchangeably used with Internet skills (Litt, 2013) and they have been found to be highly correlated, leading to model 
misspecifications (Blank and Lutz, 2018). In contrast, we found that more than Internet efficacy, it is perceived learning capability that actually leads to skills.

Our conceptualization of efficacy as a cognitive resource that precedes skills is congruent with the human ecological approach. This approach enables the observation of how people follow certain actions in order to reach their self-determined goals. The efficacy construct is a key factor in SCT for explaining human agency, as people who believe they do not have the capacity to produce the results they desire will not attempt to make them happen (Bandura, 1997: 3).

In sum, this study found that as parents faced material access barriers, they sought ways to circumvent those barriers in order to achieve their parent-child communication goals. Although most times they were able to keep in touch with their children, the nature of their interactions was still affected, most likely not reaching their communication goals. Their material access barriers, despite the alternative resources used, affected the frequency and nature of their contact. Cognitive barriers affected the acquisition of skills. However, contrary to other studies, cognitive barriers were less related to the social support individuals received when trying to gain skills and more to learning efficacy beliefs, a cognitive resource that affected their skills learning processes and, ultimately, their mobile phone use.

\section{Limitations and Future Studies}

Not accounting for differences in parents' motivation levels and how motivations influenced the different ways in which parents sought to overcome access barriers and connect with their children can be construed as a limitation of the present study. Parents guided by monitoring motivations might be more invested in finding ways to gain material access, as their communication objective presents a sense of urgency. This is not necessarily the case for parents driven by affection motivations. Qualitative studies that delve into the motivations of parents and how those translate 
into actual communication behaviors will shed light onto the meaning parents give to their parentchild interactions. Quantitative studies should then examine how the strength of various motivations influence the circumvention of access barriers or the use of mobile phones.

The qualitative phase of the study did not detail enough the different strategies parents employ when using their mobile phone in public spaces. More studies should look at how environmental barriers, such as safety concerns, affect parents' decisions to get their children mobile phones, their strategies to still connect with their children, and their communication objectives.

Also, other mediation models could be tested using parent-child communication frequency as an outcome variable. It might be the case that frequency of social connection and PAC venue uses mediate the relationship between financial barriers and communication frequency.

The relationship found between financial barriers and parents' mobile interaction with their children does not exclude the possibility this might be a spurious relationship. It might be that the type of job that parents have affects both the amount of financial resources and the frequency of communication, as low skills jobs allow for less interruptions and are paid less. A replication of this study could include categories of jobs as controls to account for this potential confounding factor.

The measurement of financial barriers variables showed a low reliability score, as we combined perceptions of costs for mobile phones minutes and for smartphones data plans. A more robust operationalization should be developed.

The question about how the barriers uncovered in this study affect the communication and relationship between parents and children remains unanswered. This study took a step forward in 
this direction by identifying how parents circumvent access barriers, but the interactions with their children are still affected by these barriers.

\section{ACKNOWLEDGEMENTS}

Special thanks to Alicia Duran and Nathaly Quiroz for their work during the qualitative phase, and to Camilo Lizarazo and Maria Paula Casas for their support in the quantitative phase of the study. Thanks to Jeff Hall for his key feedback to an earlier version of the manuscript, and to Lindsay Harroff for her support in copyediting an earlier version. Special thanks to the anonymous reviewers. Their comments allowed me to improve the quality of this article.

\section{FUNDING}

This study was funded with money from a faculty research grant from the Universidad Javeriana in Bogota, Colombia.

\footnotetext{
${ }^{1}$ The names are fictional.

${ }^{2}$ Original quotes were translated from Spanish.

${ }^{3}$ In Colombia, high-school goes from $6^{\text {th }}$. to $11^{\text {th }}$. grade.

${ }^{4}$ Social stratum was determined by asking participants in what strata was their household located.

${ }^{5}$ No data imputation to missing data was performed. Some participants did not provide an answer for some items in the learning efficacy, skills, environmental and financial barriers or on the frequency of mobile text messaging, PAC venue use and parent's own mobile communication frequency. Missing data was handled using pairwise deletion method.
}

\section{References}

Andersen R (2008) Modern Methods For Robust Regression. SAGE.

Anderson M (2017) Digital divide persists even as lower-income Americans make gains in tech adoption. In: Pew Research Center. Available at: http://www.pewresearch.org/facttank/2017/03/22/digital-divide-persists-even-as-lower-income-americans-make-gains-intech-adoption/ (accessed 22 March 2017).

Bandura A (1997) Self-Efficacy: The Exercise of Control. Worth Publishers.

Barbato CA, Graham EE and Perse EM (2003) Communicating in the family: An examination of the relationship of family communication climate and interpersonal communication motives. Journal of Family Communication 3(3): 123-148. DOI: 10.1207/S15327698JFC0303_01. 
Baron LF and Gomez R (2013) Relationships and connectedness: Weak ties that help social inclusion through public access computing. Information Technology for Development 19(4): 271-295. DOI: 10.1080/02681102.2012.755896.

Baron-Porras LF and Gomez R (2012) Same But Different: Comparing Public Access Computing Venues in Colombia (English). Information Technologies \& International Development 8(4): 43-57.

Barron CM (2014) 'I had no credit to ring you back': Children's strategies of negotiation and resistance to parental surveillance via mobile phones. Surveillance \& Society; Newcastle upon Tyne 12(3): 401-413.

Blank G and Lutz C (2018) Benefits and harms from Internet use: A differentiated analysis of Great Britain. New Media \& Society 20(2): 618-640. DOI: 10.1177/1461444816667135.

Blumer H (1986) Symbolic Interactionism: Perspective and Method. University of California Press.

Christensen TH (2009) 'Connected presence' in distributed family life. New Media \& Society 11(3): 433-451. DOI: 10.1177/1461444808101620.

Correa T (2014) Bottom-up technology transmission within families: Exploring how youths influence their parents' digital media use with dyadic data. Journal of Communication 64(1): 103-124. DOI: 10.1111/jcom.12067.

Correa T and Pavez I (2016) Digital inclusion in rural areas: A qualitative exploration of challenges faced by people from isolated communities. Journal of Computer-Mediated Communication 21(3): 247-263. DOI: 10.1111/jcc4.12154.

Creswell JW (2014) Research Design: Qualitative, Quantitative, and Mixed Methods Approaches. SAGE.

Crosswhite JM, Rice D and Asay SM (2014) Texting among United States young adults: An exploratory study on texting and its use within families. The Social Science Journal 51(1): 70-78. DOI: 10.1016/j.soscij.2013.10.002.

DANE (n.d.) Estratificación social en Colombia. Available at: https://www.dane.gov.co/files/geoestadistica/Preguntas_frecuentes_estratificacion.pdf (accessed 12 June 2015).

DANE (2015) Bogota, D.C. Pobreza monetaria 2014. Available at: https://www.dane.gov.co/files/investigaciones/condiciones_vida/pobreza/Bogota_Pobrez a_2014.pdf (accessed 15 February 2017).

De Souza e Silva A, Sutko DM, Salis FA, et al. (2011) Mobile phone appropriation in the favelas of Rio de Janeiro, Brazil. New Media \& Society 13(3): 411-426. DOI: 10.1177/1461444810393901. 
Devitt K and Roker D (2009) The role of mobile phones in family communication. Children \& Society 23(3): 189-202. DOI: 10.1111/j.1099-0860.2008.00166.x.

Dillman D (2007) Mail and internet surveys: the tailored design method. 2 ed., 2007 update with new Internet, visual, and mixed-mode guide. Hoboken, NJ, USA: Wiley.

DiMaggio P, Hargittai E, Celeste C, et al. (2004) Digital inequality: From unequal access to differentiated use. In: Neckerman K (ed.) Social inequality. New York, N.Y.: Russell Sage Foundation.

Direccion de Investigacion Criminal e Interpol-Policia Nacional de Colombia (2017) Consolidado de delitos, 2016. Bogota, Colombia: Policia Nacional de Colombia.

Direccion de Investigacion Criminal e Interpol-Policia Nacional de Colombia (2018) Hurto de celulares, 2017. Bogota, Colombia: Policia Nacional de Colombia.

Eastin MS and LaRose R (2000) Internet self-efficacy and the psychology of the digital divide. Journal of Computer-Mediated Communication 6(1): 0-0. DOI: 10.1111/j.10836101.2000.tb00110.x.

Gonzales AL (2014) Health benefits and barriers to cell phone use in low-income urban U.S. neighborhoods: Indications of technology maintenance. Mobile Media \& Communication 2(3): 233-248. DOI: 10.1177/2050157914530297.

Guest G, MacQueen KM and Namey EE (2011) Applied Thematic Analysis. SAGE.

Hall JA and Baym NK (2012) Calling and texting (too much): Mobile maintenance expectations, (over)dependence, entrapment, and friendship satisfaction. New Media \& Society 14(2): 316-331. DOI: 10.1177/1461444811415047.

Hampton KN (2010) Internet use and the concentration of disadvantage: Glocalization and the urban underclass. American Behavioral Scientist 53(8): 1111-1132. DOI: Article.

Hargittai E (2010) Digital Na(t)ives? variation in internet skills and uses among members of the "Net Generation"*. Sociological Inquiry 80(1): 92-113. DOI: 10.1111/j.1475682X.2009.00317.x.

Hargittai E and Hinnant A (2008) Digital inequality differences in young adults' use of the Internet. Communication Research 35(5): 602-621. DOI: 10.1177/0093650208321782.

Helsper EJ (2012) A corresponding fields model for the links between social and digital exclusion. Communication Theory 22(4): 403-426. DOI: 10.1111/j.14682885.2012.01416.x.

Helsper EJ and Eynon R (2013) Distinct skill pathways to digital engagement. European Journal of Communication 28(6): 696-713. DOI: 10.1177/0267323113499113. 
Hessel H, He Y and Dworkin J (2016) Paternal monitoring: The relationship between online and in-person solicitation and youth outcomes. Journal of Youth and Adolescence: 1-12. DOI: $10.1007 / \mathrm{s} 10964-016-0490-6$.

Honicke T and Broadbent $\mathrm{J}$ (2016) The influence of academic self-efficacy on academic performance: A systematic review. Educational Research Review 17: 63-84. DOI: 10.1016/j.edurev.2015.11.002.

INRIX (2016) INRIX Global traffic scorecard. Available at: http://inrix.com/scorecard/ (accessed 17 January 2018).

ITU (2014) The world in 2014: ICT facts and figures. Geneva, Switzerland: International Telecommunication Union. Available at: http://www.itu.int/en/ITU-

D/Statistics/Documents/facts/ICTFactsFigures2014-e.pdf (accessed 2 July 2014).

Katz VS and Gonzalez C (2016) Community variations in low-income latino families' technology adoption and integration. American Behavioral Scientist 60(1): 59-80. DOI: 10.1177/0002764215601712.

Konok V, Gigler D, Bereczky BM, et al. (2016) Humans' attachment to their mobile phones and its relationship with interpersonal attachment style. Computers in Human Behavior 61(Supplement C): 537-547. DOI: 10.1016/j.chb.2016.03.062.

Ling L (2006) Life in the nomos: Stress, emotional maintenance, and coordination via the mobile telephone in intact families. In: Kavoori AP and Arceneaux N (eds) The Cell Phone Reader: Essays in Social Transformation. Peter Lang, pp. 61-84.

Litt E (2013) Measuring users' internet skills: A review of past assessments and a look toward the future. New Media \& Society 15(4): 612-630. DOI: 10.1177/1461444813475424.

Lopez-Fernandez O, Honrubia-Serrano L, Freixa-Blanxart M, et al. (2013) Prevalence of problematic mobile phone use in British adolescents. Cyberpsychology, Behavior, and Social Networking 17(2): 91-98. DOI: 10.1089/cyber.2012.0260.

Madianou M and Miller D (2011) Mobile phone parenting: Reconfiguring relationships between Filipina migrant mothers and their left-behind children. New Media \& Society 13(3): 457-470. DOI: 10.1177/1461444810393903.

Mascheroni G and Ólafsson K (2015) The mobile Internet: Access, use, opportunities and divides among European children. New Media \& Society: 1461444814567986. DOI: $10.1177 / 1461444814567986$.

Miles MB and Huberman AM (1999) Qualitative data analysis. Thousand Oaks: SAGE.

MinTIC (2015) Estadísticas del sector TIC. Available at: http://estrategiaticolombia.co/estadisticas/stats.php?s=1 (accessed 19 March 2015). 
Onwuegbuzie AJ and Leech NL (2006) Validity and qualitative research: An oxymoron? Quality \& Quantity 41(2): 233-249. DOI: 10.1007/s11135-006-9000-3.

Palinkas LA, Horwitz SM, Green CA, et al. (2013) Purposeful sampling for qualitative data collection and analysis in mixed method implementation research. Administration and Policy in Mental Health and Mental Health Services Research: 1-12. DOI: 10.1007/s10488-013-0528-y.

Park YJ (2015) My whole world's in my palm! The second-level divide of teenagers' mobile use and skill. New Media \& Society 17(6): 977-995. DOI: 10.1177/1461444813520302.

Park YJ and Mo Jang S (2014) Understanding privacy knowledge and skill in mobile communication. Computers in Human Behavior 38: 296-303. DOI: 10.1016/j.chb.2014.05.041.

Pearce KE (2013) Phoning it in: Theory in mobile media and communication in developing countries. Mobile Media \& Communication 1(1): 76-82. DOI: $10.1177 / 2050157912459182$.

Ribak R (2009) Remote control, umbilical cord and beyond: The mobile phone as a transitional object. British Journal of Developmental Psychology 27(1): 183-196. DOI: 10.1348/026151008X388413.

Rudi J, Dworkin J, Walker S, et al. (2015) Parents' use of information and communications technologies for family communication: differences by age of children. Information, Communication \& Society 18(1): 78-93. DOI: 10.1080/1369118X.2014.934390.

Sampson RJ (2012) Great American City: Chicago and the Enduring Neighborhood Effect. University of Chicago Press.

Schon J (2014) "Dad doesn't text" examining how parents' use of information communication technologies influences satisfaction among emerging adult children. Emerging Adulthood 2(4): 304-312. DOI: 10.1177/2167696814551786.

Secretaría Distrital de Educación de Bogotá (2017) Directorio unico de establecimientos educativos de Bogotá. Available at: https://dueb.educacionbogota.edu.co/Dueb/ (accessed 26 October 2017).

Secretaria Distrital de Movilidad (2016) Encuesta de movilidad, 2015. Bogota, Colombia: Secretaria Distrital de Movilidad. Available at: http://www.movilidadbogota.gov.co/web/?q=node/1990 (accessed 17 January 2018).

Secretaría Distrital de Planeación de Bogotá (2015) Encuesta multiproposito 2014. Bogota, Ciudad de Estadisticas 65, May. Bogota, Colombia: Secretaría Distrital de Planeación de Bogotá. Available at: http://www.sdp.gov.co/portal/page/portal/PortalSDP/Encuesta_Multiproposito_2014/Res ultados_2014/Boletin_Resultados_Encuesta_Multiproposito_2014.pdf (accessed 15 February 2017). 
Selwyn N (2004) Reconsidering political and popular understandings of the digital divide. New Media \& Society 6(3): 341-362. DOI: 10.1177/1461444804042519.

Seo DG, Park Y, Kim MK, et al. (2016) Mobile phone dependency and its impacts on adolescents' social and academic behaviors. Computers in Human Behavior 63(Supplement C): 282-292. DOI: 10.1016/j.chb.2016.05.026.

Steinberg L (2001) We know some things: Parent-adolescent relationships in retrospect and prospect. Journal of Research on Adolescence 11(1): 1-19. DOI: 10.1111/15327795.00001 .

UN-Habitat-United Nations Human Settlements Programme (2011) Gini coefficients for selected cities and provinces. Available at: https://unhabitat.org/ (accessed 18 October 2017).

Ureta S (2008) Mobilising poverty?: Mobile phone use and everyday spatial mobility among low-income families in Santiago, Chile. The Information Society 24(2): 83-92. DOI: 10.1080/01972240701883930.

Van Deursen AJAM, Courtois C and van Dijk JAGM (2014) Internet skills, sources of support, and benefiting from Internet use. International Journal of Human-Computer Interaction 30(4): 278-290. DOI: 10.1080/10447318.2013.858458.

Van Deursen AJAM and Helsper EJ (2017) Collateral benefits of Internet use: Explaining the diverse outcomes of engaging with the Internet. New Media \& Society: 1461444817715282. DOI: 10.1177/1461444817715282.

Van Deursen AJAM and Helsper EJ (2015) The third-level digital divide: Who benefits most from being online? In: Communication and Information Technologies Annual. Studies in Media and Communications 10. Emerald Group Publishing Limited, pp. 29-52. Available at: http://www.emeraldinsight.com/doi/full/10.1108/S2050206020150000010002 (accessed 9 July 2016).

Van Deursen AJAM, Helsper EJ and Eynon R (2016) Development and validation of the Internet Skills Scale (ISS). Information, Communication \& Society 19(6): 804-823. DOI: 10.1080/1369118X.2015.1078834.

Van Dijk JAGM (2005) The Deepening Divide: Inequality in the Information Society. SAGE.

Van Dijk JAGM and Van Deursen AJAM (2014) Digital Skills: Unlocking the Information Society. New York, NY: AIAA.

Velghe F (2012) Deprivation, distance and connectivity: The adaptation of mobile phone use to a life in Wesbank, a post-apartheid township in South Africa. Discourse, Context \& Media 1(4): 203-216. DOI: 10.1016/j.dcm.2012.09.004.

Wajcman J, Bittman M and Brown JE (2008) Families without borders: Mobile phones, connectedness and work-home divisions. Sociology 42(4): 635-652. DOI: 10.1177/0038038508091620. 
Wei R and Lo V-H (2006) Staying connected while on the move: Cell phone use and social connectedness. New Media \& Society 8(1): 53-72. DOI: 10.1177/1461444806059870. 